friends that they are quite well, and the general medical public do not at present comprehend the grave character of these voices. My own belief, however, is, that the tendency of such patients is to get worse, that the power of repressing the voices and their suggestions becomes less and less, and that, in the majority of instances, the mental health is undermined by the constant worry and loss of rest and sleep brought about by them. The diagnosis of these hallucinations is often difficult, for patients will not always confess them. Much may be learned by observation of them when alone, for then they are most likely to listen for and answer the voices. And often we may detect a patient listening even while talking to us, and, by narrowly watching, may ascertain the existence of hallucinations, which may be quite unknown to the friends and relatives.

In my experience I have found these voices more common in chronic female patients than in male. Of 34 ladies now in an asylum, not less than 14, and possibly 16, hear them, while of 43 gentlemen I cannot be sure of their presence in more than nine. These numbers are, of course, very small for statistical purposes. I should be glad to hear the experience of those who have under their observation large numbers of the insane.

The Perception, \&c., of Time as a feature in Mental Disease. By W. A. F. Browne, Psychological Consultant to the Crichton Institution. Late Commissioner in Lunacy for Scotland, \&c.

(Read before the Quarterly Meeting of the Medico-Psychological Association at Edinburgh, November 27th, 1873.)

The power or process by means of which Time is mentally recognised and estimated independently of, or before, its external and artificial measurement, has not received a clear or comprehensive solution at the hands of those who have dealt with the subject. Certain metaphysicians connect the idea of duration with that of extension, and conceive that the child, or the savage, may have acquired a notion of intervals, or interrupted extension, from seeing and feeling through the muscular sense the alternate extension and flexion of his limbs; all comparison of such events with the successive changes in objective phenomena, as in days and nights, being the result of subsequent experience. Certain 
others conceive that our notion of Time originates in our consciousness and observation of succession in our thoughts, feelings, and mental states, a succession which necessarily involves a series of changes separated in time, and order, and nature. Sir W. Hamilton, apparently aware of the difficulty of the problem, says that " Time is a form of thought," and " if we attempt to comprehend Time, either in whole or in part, we find that thought is hedged in between two incomprehensibles." Other philosophers, belonging to a more practical school, who may be claimed as psychologists, contend that the subjective element of Time is imparted by the communication of impressions upon the external senses to the sensorium, coming as these must always do in succession with intervals of different length, and, as they often do, of regular length and intensity. It will be observed that in all these hypotheses it is taken for granted that the mind is capable of directing attention to its own conditions, and, to a certain extent, of analysing these, of marking their course, their swiftness, or slowness, their regularity, or irregularity. On the other hand, the phrenologists contend that there is a primitive and special faculty connected with a portion of the anterior lobe of the brain, by which Time, or the succession of events and intervals, is perceived or becomes known to us. My own speculations formerly led me to the theory that the perception of rhythm, or regular sequence, in sensorial impressions was conveyed by the pulsations of the cerebral arteries, either to the whole brain, or to such portion of it as may take cognisance of internal movements or changes. Sir H. Holland, that noble veteran, that learned and travelled and philosophic physician, who has just passed from amongst us, dedicated a chapter in his "Medical Notes and Reflections,"p. 499, to the exposition of "Time as an element in Mental Functions," in which his chief object is to show that ideas or different modes of mentalisation arise and are propagated in different degrees of velocity and intensity in Time in different temperaments, and in the same individual at different periods, in accordance with the predominant physical or mental condition.

But whether the Perception now under consideration be an intuition, an inference drawn from reflection, or be the result of structural or what are vaguely called molecular alterations in the brain, experience shows that different individuals are endowed with the power in various degrees of strength and range, as is perhaps best exemplified by the 
difference which obtains in the estimate by different individuals of the variation of Time in the transit of a star across the micrometer thread of a fixed telescope. Physical disease lays bare the fact that during the course of fever, especially of puerperal fever, there is a total, or partial, loss of the appreciation of the lapse of time. Days, weeks, months are blotted out from the Calendar of Life. There is an inability to mark the sensations which constitute the stages of decay or recovery, even to note the hours and days recorded by the ordinary mechanical means. Even in health and vigour persons are met with who have little or no knowledge of the changes going on in their own constitutions, of the appointed periods and seasons in social arrangements; who never are aware of the duration of days, hours, minutes, and who are regulated by habit and imitation rather than by an apportionment of Time. It is asserted that our Celtic forefathers were defective in the computation of Time, and calculated "days, and years, and ages past," by signal events, catastrophes, or cataclysms, rather than by divisions in Time. A similar allegation is made as to uncivilised races. Galton says * - "We had to trust to the guides, whose ideas of time and distance were most provokingly indistinct. They have a very poor notion of Time. If you say, 'Suppose we start at sunrise, where will the sun be when we arrive? they make the wildest points in the sky, though they are something of astronomers, and give names to several stars. They have no way of distinguishing the days of the year, but reckon by the rainy season, the dry season, or the pig-nut season." At the opposite extremity of the scale may be placed the celebrated Lord Stowell, "who could at all times state the precise hour, or minute, without reference to clock, watch, or any artificial means of measurement ;" $\dagger$ and the equally interesting, though not so celebrated, human timepiece, Chavalley, $\ddagger$ who, though deaf, by what he designated "an internal movement, or profound calculation, which neither thought, nor labour, nor anything, could stop, possessed the power to indicate, to a crowd around him, the passing of a quarter of an hour, or as many minutes, or seconds, as anyone chose, and that during conversations the most diversified and notwithstanding the recourse to every means by which his attention might be diverted." When tested by a scientific

* "Narrative of an Explorer in Tropical S. Africa," 1853, p. 182.

f "Recollections of Past Life," by Sir Henry Holland, 1872, p. 195.

I "Bibliothèque Universelle," vol. 27. 
observer, M. Chavannes, "he shook his head at the time appointed, altered his voice at the quarter, half, and threequarter minutes, and arrived accurately at the end of the period named." It would appear that this singular faculty continued in operation during the night, and during sleep, and that, provided his slumbers were not profound, nor had followed fatigue and exhaustion, he could within a very brief period after awakening indicate within a very few minutes what time had passed, or, in other words, how long he had been unconscious. In the infant and undeveloped mind instances of precocity in the perception of time, so far as musical intervals are concerned, are frequent. Crotch played the organ at three years old; Mozart acquired a knowledge of music by imitations of his sister at three years old, composed at five; Handel was sensible of musical intervals and practised on a deafened clarichord at three, and played the harpsichord and organ at first sight when seven years old; and Brigham mentions a hydrocephalic child who sang and kept time when he reached the age of fifteeen months.* Even where the intelligence is limited and ineducable similar peculiarities have been noticed; idiots are to be met with who display, though unable to interpret our means of measurement, an accurate knowledge of regular intervals and of the passage of Time; and every asylum and school may afford examples where an accurate rhythm is preserved in their oscillations. It has been affirmed that such movements, as well as those exhibited in malleation, in the alternate pronation and supination of modifications of chorea, \&c., are performed at a distance of time precisely equal. $t$ This is perhaps correct when the observation is confined to a single individual, but the succession of acts raries greatly in rapidity in different individuals and in different forms of disease. Our inquiries, however, will withdraw us from the contemplation of what may be regarded as the normal manifestations of the perception of Time, and lead us to phenomena indicating the enfeeblement, or exaggeration, of this power; its morbid influence, either in compliance with, or in opposition to, volition, and as demonstrated in acts, habits, and muscular movements. The most notable illustrations of the association of regular intervals, or the succession of events in Time,

- "Remarks on the Influence of Mental Cultivation and Mental Excitement." 1836, p. 27.

$t$ Much information on this point is contained in Professor Layoock's "Nervous Diseases of Women." 
will be found in the periodic, or paroxysmal, character of certain nervous affections, and of the Folie circulaire ou d double forme* of the French. Besides the more striking illustrations, we have noted periodic laughter, periodic expressions, periodic micturitiont. Conolly attended a case of epilepsy which assumed, in the return of convulsions, a tertian type; and it is well ascertained that in marshy countries the neuroses are apt to take on an intermittent form. But the subject is too vast and too profound to be embraced here, and we shall confine these remarks to cases in which Time enters as a feature, or a symptom, of disease, and where it is independent of the characteristics of the class neurosis, and, to a certain extent, of the diathesis of the patient.

Everyone must be aware that as we recede from particular seasons and circumstances memory fails to recall them in their original distinctness and vividness; indeed, as age advances large portions of our personal history are deleted altogether. But under the pressure of disease there occur large gaps, with sharply defined limits, up to one side of which every event is faithfully and accurately recollected, and beyond which the recollections are equally clear and truthful ; but between which all is vacuous, unfathomable, and irrecoverable. When this loss of time and everything by which it was marked occurs in Mania, it may fairly be attributed to the extreme rapidity and tumultuousness with which thoughts and feelings follow each other, and the inability of attention to mark the members of the series, for they have no sequence, and, if the expression may be allowed, to commit them to memory; when in Dementia, it is obviously owing to the absence of subjective states in consciousness, and to the obtuseness of perception in receiving and registering external impressions. Such losses are frequent in the advanced stage of General Paralysis and Epilepsy, even while places, persous, and events are still remembered. When occurring in Monomania the hiatus is the result of delusion; and when in that rare Psychose, Double Consciousness, the oblivion of the one state alternates regularly with the supervention of the other.

About twenty years ago, I became acquainted with a lady who, after recovering from an attack of what may be called

" "Traité des Maladies Mentales," par M. le Dr. B. A. Morel, p. 474.

$\uparrow$ I am indebted for an example of the latter to Dr. Anderson, Southern Counties Asylum, Crichton Institution.

VOL. XIX. 
Hysterical Fatuity, had lost twenty years of her previous existence, although that period had included her youth, courtship, and marriage. She had to recommence the education of the senses, as well as of the affections and intellect; never regained any conception of her previous relations to the world, society, or her family, and never recognised her husband. Dr. Abercrombie* says, "A lady whom I attended some years ago in a protracted illness, in which her memory became much impaired, lost the recollection of a period of about ten or twelve years, but spoke with perfect consistency of things as they stood before that time." He mentions several other apposite instances, and quotes Dr. Beattie as to a gentleman, "who on recovering from an apoplectic attack was found to have lost the recollection of exactly four years; everything that occurred before that period he remembered perfectly." I have, within the last week, lost a patient who has been in seclusion for thirty-eight years. This man was well educated and acute; after a brief paroxysm of mania he became a Theomaniac; but, amid the most absurd, heterogeneous delusions as to his divinity, translation to Heaven, \&c., there was conspicuous the fact that he had lost an entire year, that there was obliterated from his mind 1836, although during it had grown up to maturity his second nature.

Inmates of asylums are often to be met with who have abandoned our calendar, who have lost, or transposed, days and weeks ; who declare Tuesday, or Saturday, to be Sunday; and there has recently been submitted to me the sketch of a female, in confinement, who, being 70, declares that she is $\mathbf{1 0 3}$ years old, and says that she has counted every day of it. Her general memory and intelligence are perfectly clear. She avers that February is the only true month, and that all the others are liars; her aphorism being seven days in a week, four weeks in a month, twelve months in a year. Acting upon this datum she counts the days and months, and has got all wrong in her calcula. tion. For instance, when she comes to the 28th of Oct., she says the month is finished, and the next day, really the 29th of Oct., she calls the 1st of Nov. She has been carrying on this misleading system for thirty years.

Several dements have come under my notice who, by some mnemonic memory, the rationale of which I could not penetrate, retained a perfect knowledge of the dates of " " On the Intellectual Powers," 1831, p. 161. 
great events, and could tell precisely the rear, day, and hour, of a great catulle or catastrophe, realising the ideal of Mumblazon in "Kenilworth ;" but who had lost every connecting link or separating convulsion which could lead to, or suggest, the different points of time, or history, in their chronology. There is another and very opposite condition to that in which the circuits of the years leave no "footsteps on the sands of time," where there is an exaggeration, an imaginary extension, of years, even of centuries, through which reminiscence travels back, gathering up fragments as proofs and monuments of its vast duration and experience. In Melancholia this erroneous measurement of suffering may originate in the prolonged extension of one unvarying misery, and in the sustained concentration which the endurance of pain calls forth. In Monomania the conviction will proceed not from miscalculation, but from a delusion that the individual is divine, immortal, has died and risen again, is Methuselah, the wandering Jew, \&c. This delusion is frequently met with in the first stage of General Paralysis. De Quincey* has described such fancies as concomitant with opium poisoning. "This, the expansion of space, disturbed me very much less than the vast expansion of time. Sometimes I seemed to have lived for seventy or a hundred years in one night; nay, sometimes had feelings representative of a duration far beyond the limits of any human experience. . . I ran into pagodas, and was fixed for centuries at the summit or in secret rooms. . . Thousands of years I lived, and was buried in stone coffins with mummies and sphinxes in narrow chambers at the heart of eternal pyramids." These, which may be legitimately called morbid impressions, must follow the long-continued saturation with the drug, as its ordinary effects are the extinction and forgetfulness of Time and space. We have had patients who witnessed the siege of Jerusalem, who fought at St. Jean d'Acre, who were crucified on Calvary, who had conversed with St. Paul ; and one good humoured, ignorant sailor who, besides keeping time in the disposal of myriads of coils of unseen and intangible rope, dated his acquaintance with me, as a practitioner, a thousand years back in Memphis, and endeavoured to prove his assertion by enumerating the medicines which I had prescribed, and the cures which I had effected.

" "Confessions of an Opium Eater." Black, Edinburgh, 1866. Pp. 259, 
All 1 address must be familiar with " the measured tread of marching men," with individuals who walk a certain number, and always the same number, of steps in the same direction, and then return ; who walk in circles or diagonally; who touch particular points or objects at given and apparently equal distances. In asylums they must have met with others who accompany such acts with certain sounds, songs, or musical accompaniments, thus extemporising some mental perception of measured intervals. A person long under my care always turned completely round in the same direction, rising on the same heel as a pivot three times before leaving an apartment. He is still alive, but has long since discontinued the practice. Another patient who, however, preferred carriage exercise, whenever he did walk strode forward in paces of exactly a yard in length, with a solemn or military cadence in the step. When he trod on carpets he invariably and carefully placed his root on similar patterns at precisely the same distance from each other. A like custom is said to have been rigidly adhered to by Dr. Samuel Johnson, who in going up St. James' Street paced as if in the ranks of a regiment, touching every lamp post which occurred in his way.

I have at present under my care a young lady who presents the following outward and visible signs of some mental process involving a modification of the measurement of Time. Although seventeen, she has the aspect of thirteen years. She is slow, sluggish, and defective in mental activity. These symptoms offer the greatest obstacles to her improvement, but her most prominent manifestations consist in her touching every object, in repeating all her acts twice, or oftener; she repeats what is addressed to her and what she answers twice. She plays over the same tune twice; she often goes back two steps on the road, then dances forward to regain her position, and walks on. She will return to touch a point omitted in advancing. In reading she repeats the same word, or sentence; in her muttered soliloquies she may be heard going over the last question addressed to her, and in all these acts there is a perceptible rhythm and alternation. She is conscious both of her torpor and eccentric doings, and even langhs at their absurdity, but feels constrained to deport herself in the manner described. Similar movements, although complicated and in one sense obscured by more startling and significant symptoms, have been recorded in former times and upon a much grander scale. 
A boy, æt. eight or nine, presented the following symptoms: - After suffering from various anomalous ailments, supposed to be nervous, he was seized with an involuntary and apparently uncontrollable tendency to leap. When attacked he threw himself upon all fours, and in this position leapt four times from left to right, and he emitted a loud inarticulate cry during each movement. The saltations were in rapid but regular succession, and this quadrupedal exercise was continued until interrupted by exhaustion, or the interference of those around. This case was examined by my colleague, Dr. Gilchrist, about the year 1855, in Montrose ; and it is worthy of remark that in Forfarshire, about fifty years before, had occurred that singular epidemic the leaping ague, which was characterised, not merely by the performance of extraordinary and perilous feats, such as climbing trees, walking scatheless along the roofs of houses, in a manner which an acrobat might have envied, but by swinging rapidly and rhythmically round the beams of the house,like a fly-jack, upon which the epigastrium rested, forming the axis of motion. The disease was confined exclusively to females, and in certain hysterical women I witnessed many of the traces or remains of the epidemic in 1835 . In one of these-a coarse but rather sensible person-the movements were rotatory and rhythmical, the feet being the pivot; they were entirely involuntary, and ceased only when vertigo, or loss of consciousness, supervened.

From a large number of instances of Trochaicism we select the following:-1. An idiot, who during his excited periods touches his knees with his right hand and lifts it to his nose regularly and rhythmically, at the same time uttering a whistling sound, with short intervals. The number of times he executes the motion irregular. 2. A dement, who plucks at his coat rhythmically, and who, at certain intervals during this act, touches his knee with his forefinger, or the button of his coat, or the top of his neighbour's head. He alsp touches the palmar aspect of the left index and middle fingers with the point of the right middle and index fingers successively, and at particular intervals touches certain parts of his head. The movements are, with little variation, performed ninety-two times in the minute. 3. An idiot moves fingers rhythmically backwards and forwards before his eyes. 4. A chronic maniac, who struck the palm of his left hand with the back of the fingers of the right, then with the front 
of his right, then with the back of his right again, and then loudly with the palm of his right again. 5. A dement, who strikes the palm of his left hand with his first and second fingers thrice, and then with his forefingers only at the fourth beat. He then makes a contortion three times in succession. 6. A Religious Maniac in speaking moves incessantly, steps alternately from side to side, as in setting to partners in a quadrille. In most instances he takes three short steps to the right, and then as many to the left, and so on alternately. Occasionally, though comparatively rarely, a fourth step is taken. Each series of three steps was completed in three seconds on the only occasion they were timed.*

It is, of course, open to question whether the gyrations in the leaping ague, \&c., were altogether independent of volition. My own experience would lead me to believe that at first, in the initiatory act, such movements are voluntary, but that ultimately, either from cerebral congestion and vertigo, or from some other cause, they pass beyond the control of the will and stand in the same relation to consciousness as the eccentric and grotesque attitudes in chorea, where muscular motion originates in volition, though its direction and continuance is regulated by other laws. A case has just been made known to me where a person labouring under organic disease of the brain moved the right arm round and round rhythmically precisely forty times per minute, and where the narrator designates the phenomenon "mechanical." This origin is " the some cause" alluded to above, or an occult, instinctive, measure of time, unknown to perception, except by its effects, which consist in successive contractions of the heart, alternate inspiration and expiration, the regular return of secretions, \&c. ; a sense which may have, rather than the vibration of the lamp in the Cathedral of Pisa, suggested to Galileo the law of oscillation, and the most perfect measure of time by the pendulum. That the leaping ague was more than a mere intense. form of chorea may be gathered from the epitomisation of a typical and comparatively recent example. Besides the irresistible propensity to dance and whirl around, A. B. leaped upon the furniture of the room, ran round a table, sprang upon the top of the door to swing backwards and forwards, leapt over a staircase at one bound, and desired to spring out of a window, spoke in language which those

*Certain of these have been supplied by Dr. Aitken, Inverness Distriot Asylum; and by Dr. Cameron, Med. Ass., Crichton Institution. 
around could not understand, wrote from right to left, and both in speaking and writing transposed the letters of each word, so that the last became the first. *

Dancing was the characteristic of that epidemic madness which disturbed and desolated Germany, the Netherlands, and Italy during the thirteenth, fourteenth and fifteenth centuries. It is not necessary at present to distinguish the dance of St. Vitus, or St. Guy, from Tarantism, or the Tigritia of Abyssinia. In all of these affections, which spread to hundreds and thousands of the population, both Teutonic and Celtic, children and octogenarians, there were observed wild and exuberant excitement, delusion, and antipathies with uncontrollable impulses to run, leap, all such movements ultimately passing into dancing, which was generally aggravated, though sometimes mitigated, by music. These dancers were impelled, sometimes by imitation, sometimes by fanatical exultation, sometimes by terror and the fear of being poisoned, and it was when under the latter emotion that harmony seems to have been most powerful and curative. Airs have been preserved which were employed as antidotes in arresting or moderating the frenzied rotations and leaps of those urged on by dread of the bite of the Tarantula and by other causes; and that some interference was required is evident, for although large numbers of those affected recovered, many resisted all coercion, and danced themselves to death. These tunes which were regarded as remedial are said to have been of peculiar character, and to have contained transitions from a quick to a slow measure, and to have passed gradually from a high to a low key. The sensibility to music was so great that at the very first tones of their favourite melodies the affected sprang up, shouting for joy, and danced on without intermission until they sank to the ground, exhausted and almost lifeless. Although thus excitable, no external or audible music was requisite to suggest or sustain such movements. Apparently stimulated and guided by some internal rhythm, the performers danced, sometimes with infuriated, but always with measured steps, wheeling hand in hand in circles, not merely from street to street, but from town to town, dropping down when exhausted, but having their places supplied by fresh recruits. When under this inspiration the most rude and untrained victims exhibited gracefulness, even elegance, in the dances, and manifested disquiet and abhorrence when false notes

"Vide Crichton, "Edinburgh, Medical and Surgical Journal," vol 31, p. 299. 
were introduced into the music. Besides displaying unequivocal symptoms of insanity in various forms, and in the most fearful and formidable intensity, these sufferers presented various peculiarities which seemed to connect their condition with that known to exist in other psychoses, such as intolerance of certain colours, creeping on all fours like the Lycanthropes of the Jura, genuine choreaic gesticulations, touching particular objects four times in succession and at regular intervals, as was seen in the leaping ague. While we are altogether sceptical that the fantastic and fatal dances were caused by the bite of the Tarantula, and are somewhat doubtful as to the ratio medendi of the Tarantella, there is no doubt whatever that a wide-spread disease, marked by rhythmical movements and influenced by music, existed in Apulia, and it is not a little striking that, subsequently, the Asylum at Aversa in the same kingdom obtained great celebrity, which has outlived its cause, by the treatment of mental diseases by music, by swinging of the cots in which the patients were placed to and fro at measured intervals, and so on.

In modern times similar conditions have been treated by similar means. A. W., æt 22, was in 1816 seized with chorea. She struck the furniture violently and repeatedly ; kneeling upon one knee she sprung up and struck the ceiling; to do this she rose 15 inches from the floor; she frequently danced upon one leg, holding the other with the hand, and occasionally changing the legs; subsequently her family observed that the blows on the furniture were more continuous, and assumed the regular time and measure of a musical air, and that her leaps were regulated by the succession of the strolies upon surrounding objects. Her lips were observed to move as if in harmony with her steps and strokes, and ultimately her progression became a graduated march, or resembled the figure of a minuet or of a country dance. A spectator conceiving that he recognised the tune imitated by her blows upon the door, table, \&c., sung it, when she immediately began to dance, and continued to dance until he was exhausted. A drum and fife were now introduced, the sounds of which invariably induced dancing, and attracted her towards the instruments. Whenever she lost the step or a false note occurred, she ceased to move. She confessed to her medical man that a tune was ever present in her mind, and was occasionally so powerful as to compel involuntary movements. It was discovered that when the drum was beat 
in a continuous roll, instead of a tune, the motions instantly ceased, and this interruption to the morbid associations, upon which the disease was supposed to depend, having been transferred to the commencement of each attack all involuntarily action was at last permanently arrested. It is noteworthy that when pacing in her stately manner each stride placed the foot upon the joinings of the stone flags, particularly when she looked downwards.*

That, apart altogether from the measurement of intervals by the aid of successive mental states, or a special faculty, and likewise apart from all morbid exaltation of such means, there exists in the healthy and robust mind a certain rhythm, might be demonstrated in various ways, but I shall content myself with the following illustrative narrative: $†$ "Mezzofanti had the habit of thinking, when alone, in each and all of his various languages in succession, so that, without the presence of a second individual, he almost enjoyed the advantage of practice in conversation." The only parallel for this extraordinary mental phenomenon, that I know, is a story which I somewhere read of a musician who attained to great perfection as an instrumental performer, though hardly ever known to touch an instrument for the purpose of practice. This man, it is said, was constantly practicising in his mind, and his fingers were actually observed to be always in motion, as though engaged in the act of playing.

About twenty years ago there was placed under my charge a gentleman whose proteiform malady presented many of the features which have been described. J. M., æt. 37, an officer in the Austrian army, who had five brothers or sisters of unsound mind, was supposed to have induced mental unsoundness by gross debauchery. He laboured at one time under violent mania; then under panphobia, in violent paroxysms; then under partial fatuity, with delusions. $\mathrm{He}$ was attacked repeatedly by epileptiform convulsions; he was cataleptic, holding the hands upright, or in some awkward position for long periods; he was choreaic when he tossed from one side to another, assumed absurd and dangerous attitudes ; he was in the habit of executing repeated summersaults; he was subject, before or after fits, to symmetrical movements of the arms and head, synchronous with respira-

"Transactions of the "Medico-Chirurgical Society," vol. 7, p. 519. Dr. Kinder Wood.

$t$ " Life of Mezzofanti," p. 477. 
tion, striking his chest with each hand alternately, and at regular intervals; and frequently, when not excited nor comatose, his fore-arms revolved round each other with a rapidity and force which could with difficulty be checked. The circular action was renewed whenever the obstacle was removed, and was at all times regular and rhythmical in interval. He appeared constrained to imitate the gait and manner of those around, and gave way to loud vociferations or ullulations.

I would not venture from the preceding narratives to draw dogmatic conclusions, but conceive that from them, and from collateral considerations, we are entitled to infer that, as the subjective measurement of time occurs in imperfect and rudimentary minds, and instinctively, it cannot depend upon any act of consciousness in noting the succession of mental states, although the phenomena of abstraction, concentration, mono-ideism when the mind is fixed upon one particular object, as then all conception of the passage of time is shut out, appear to countenance such a supposition. 2ndly. That the condition and the confession of the choreaic A. W., the accurate and graceful dancing of the deaf and dumb, \&c., set aside the hypothesis as to the regular succession of external impressions; and 3rdly, that the bearing of all these observations would induce a belief in the existence of a time-perceiving and time-regulating power, either created and conducted by some physico-psychical operation, or by intuitions similar to those which recognise the relations cf number, \&c., and which certainly depend upon the integrity and activity of the whole, or of a part, of the nervous centres.

The Madmen of the Greek Theatre. By J. R. G

(Continued from page 222.)

VI. Cagsandra.-The Fragments.

The seclusion in which the women of Athens lived naturally made the elder dramatists shrink from exhibiting them on the stage as under the influence of violent passion. Euripides departed from this rule, and was lashed for it by his merciless satirist; but even he, who depicted a Medea and a Phædra, did not venture to bring a raving woman before his audience. There was just one case in which the Greeks would not be justly scandalised by such a presentment-- 

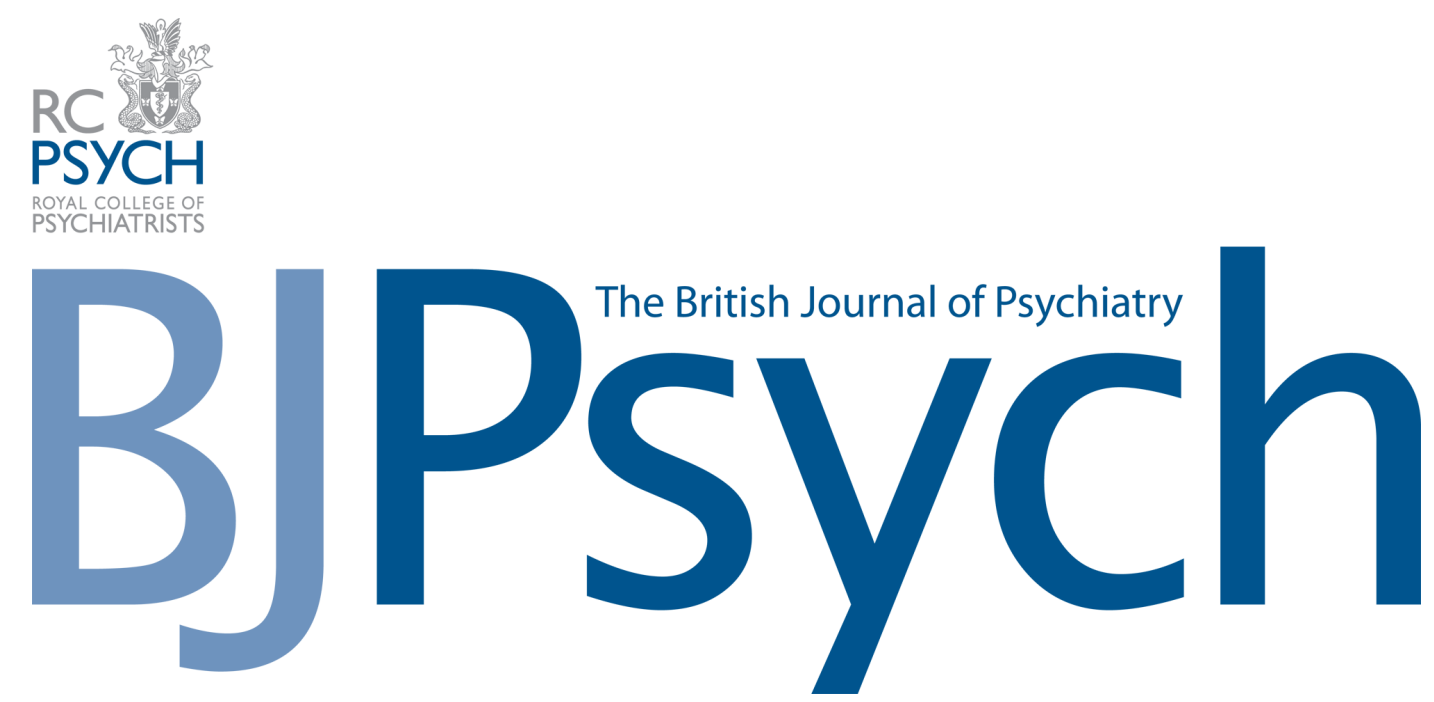

\section{The Perception, \&c., of Time as a Feature in Mental Disease}

W. A. F. Browne

BJP 1874, 19:519-532.

Access the most recent version at DOI: 10.1192/bjp.19.88.519

\begin{tabular}{cl}
\hline References & $\begin{array}{c}\text { This article cites } 0 \text { articles, } 0 \text { of which you can access for free at: } \\
\text { http://bjp.rcpsych.org/content/19/88/519.citation\#BIBL }\end{array}$ \\
$\begin{array}{c}\text { Reprints/ } \\
\text { permissions }\end{array}$ & $\begin{array}{l}\text { To obtain reprints or permission to reproduce material from this paper, please write } \\
\text { to permissions@rcpsych.ac.uk }\end{array}$ \\
$\begin{array}{c}\text { You can respond } \\
\text { to this article at } \\
\text { Downloaded } \\
\text { from }\end{array}$ & $\begin{array}{c}\text { /letters/submit/bjprcpsych;19/88/519 } \\
\text { Published by The Royal College of Psychiatrists }\end{array}$ \\
\hline
\end{tabular}

To subscribe to The British Journal of Psychiatry go to: http://bjp.rcpsych.org/site/subscriptions/ 